\title{
Inflight Parameter Identification and Icing Location Detection of the Aircraft: The Time-Varying Case
}

\author{
Yiqun Dong ${ }^{1}$ and Jianliang $\mathbf{A i}^{2}$ \\ ${ }^{1}$ Department of Mechanics and Engineering Science, Fudan University, Shanghai 200433, China \\ ${ }^{2}$ Department of Mechanics and Engineering Science, Institute of Aeronautics and Astronautics, Fudan University, \\ Shanghai 200433, China
}

Correspondence should be addressed to Yiqun Dong; yiqundong10@fudan.edu.cn

Received 9 February 2014; Accepted 19 June 2014; Published 10 July 2014

Academic Editor: Onur Toker

Copyright (C) 2014 Y. Dong and J. Ai. This is an open access article distributed under the Creative Commons Attribution License, which permits unrestricted use, distribution, and reproduction in any medium, provided the original work is properly cited.

\begin{abstract}
This paper considers inflight parameter identification and icing location detection of the aircraft in a more common time-varying nature. In particular, ice accumulation is modeled as a continuous process, and the effect of the ice upon aircraft dynamics is to be accreted with time. Time-varying case of the Hinf algorithm is implemented to provide inflight estimate of aircraft dynamic parameters, and the estimated results are delivered to a probabilistic neural network to decide icing location of the aircraft; an excitation measure of the aircraft is also adopted in the network input layer. A database corresponding to different icing cases and severities was generated for the training and test of the detection network. Based on the test results, the icing detection framework presented in this paper is believed to be with promising applicableness for our further studies.
\end{abstract}

\section{Introduction}

Current aviation research and development has begun to focus more on creating aircraft that are safe and reliable during severe weather conditions. Aircraft icing is of great concern due to the detrimental effect of accreted ice on aircraft performances. Most of the accidents related with aircraft icing occur because the ice accumulation modifies the stability and controllability of the aircraft $[1,2]$; other accidents include engine failure or critical probes (pitot tube, etc.) malfunctioning $[3,4]$. Currently there are two main approaches to deal with the ice accretion problem. First, pilots are provided with weather information prior to flight missions in the pursuit of avoiding potential icing conditions or aircraft are thoroughly deiced before takeoff, while an icing protection system (IPS) could be operated in flight to remove dangerous ice accretions.

Under all circumstances, apparently ice avoidance is a more desirable goal. For most of the commercial flight courses, however, while revenues and schedules must be maintained, IPS still occupies an important part in the insurance of safe flight. Current IPS mainly consists of devices that could bleed hot engine exhaust to counteract the frigid icing conditions, or inflatable boots are used to break off the accumulated ice. Generally the IPS functions in an either advisory or primary capacity. The advisory IPS relies upon pilots to activate icing protection devices based on any aircraft icing information, which might be allocated from icing/environmental sensors. As for IPS that functions in the primary capacity, it utilizes the information collected from various sensors, and the deice/anti-ice devices are activated automatically. Pilots are given instantaneous updates concerning aircraft icing and IPS status; they could also manually override the system if necessary.

Recently, sporadic aircraft accidents indicate that the IPS strategy does not adequately provide safe and reliable flight during icing conditions. The accident of American Eagle ATR-72 near Roselawn, Indiana, killed 68 people in October 1994 [2]. The China Eastern Airlines Flight 5210 (CRJ-200) crashed after takeoff in Baotou City in November 2004, killing 55 people. And in the year of 2009, the Air France Flight 447 (A330) crashed over the Atlantic Ocean; all the passengers on board were lost $[3,4]$. These fatal accidents are notable examples of the IPS inadequateness, where either the 
IPS was not activated timely or the IPS was activated but not effective. To ensure flight safety of the aircraft, an overall systematic inspection of the icing hazard needs to be conducted.

Back to 1994 after the ATR-72 accidents, NASA and FAA in United States cosponsored a four-year Tailplane Icing Program (TIP), which was expected to expand the understanding of the aircraft ice contaminated tailplane stall (ICTS) hazard [5]. In 1998, after the closure of TIP, Brag advanced an icing management system (IMS) as an additional layer of defense against the aircraft icing accidents [6]. IMS adopts the core effect of ice accretion upon aircraft-the modification of aircraft stability and controllability; while IMS provides a continual monitoring of the aircraft icing status, traditional IPS devices could be activated automatically by the IMS, and a reconfiguration of the inline flight control laws could be included, so as to restrict the aircraft maneuver within a proper margin of safety.

The Commercial Aircraft Corporation of China (COMAC) in Shanghai is en route to the production of China's first generation of large civil aircraft. Due to the hazardous effect upon aircraft performance and safety, ice accretion draws a strong concern from us. According to the schedule, the research work on aircraft icing mainly includes a CFD inspection of the ice accumulation and an icing wind-tunnel examination of aircraft, and real flight testing maneuvers are also necessary to either verify the wind tunnel results or evaluate the effect of ice during critical stages of the aircraft mission (e.g., landing/takeoff cycle). Lastly, a self-adaptive mechanism could be implemented in the inline flight control laws design.

The aircraft icing research in Fudan University is mainly focused on the dynamics, and in future time the control, of iced aircraft. Our current work is formulated to provide an exploration for the inflight detection/characterization of the accreted/accreting ice upon the airframe; after the overall test procedure is completed, a control aid for the pilots will be developed. In our work, similar to IMS, we adopt the core effect of ice on aircraft performance-the modification of stability and controllability. Parameter identification technique is employed to provide inline estimates of the aircraft dynamic parameters, after which the aircraft icing location and severity could be decided. In [7], we have discussed a work on inline icing location detection of the aircraft. Baseline scenario of the work was selected as trimmed steady level flight; it was assumed that the ice has completed the accumulation on the airframe, and the aircraft dynamic parameter remains time-invariant over the maneuver period. Identification maneuver was induced by separated command input of the aircraft control surfaces, in the hope that the coupling motion along different axes of the aircraft was to be suppressed. After the ID maneuver was finished, ID results were delivered to the neural network to decide icing location of the aircraft. Due to current shortness of the aircraft icing data, only four scenarios of clean, wing icing, tail icing, and wing-tail both icing cases were discussed. A very high degree of accuracy of icing location detection was accomplished in the work.

One problem of this work, however, is that it could only provide indication of the aircraft icing over short period.
Certainly the designed command input could be repeated constantly, but through simulation it was found that overload of the aircraft was relatively high, and passenger-ride quality of the aircraft shall not be guaranteed. Also a constant input of all the 3 control surfaces affects the aircraft state severely; it was hardly possible for the aircraft to maintain the initial steady level flight. In such senses, while the work discussed in [7] could be employed for detection of aircraft icing over short period, a long-period continual monitoring of icing status could not depend upon it.

And in this paper we try to fill this gap. Specifically we try to develop a framework that could continually monitor status of the aircraft, and based on all the data available, information pertaining to aircraft icing could be estimated. In Section 2 of this paper, we build up a long-period icing model of the aircraft. The icing severity was modeled to increase with time, based on which the effect of ice on aircraft dynamic parameters was to be accreted. Section 3 introduces a Hinf parameter ID technique developed for the timevarying system. This technique depends solely on exogenous disturbance signals of the system, and dynamic parameters of the system could be estimated. As this ID technique requires no specific excitation from the system input, and it adopts only the state vector of the aircraft, it arises as a perfect tool for the long-period continual monitoring task. In Section 4, based on the parameter estimation results from Hinf algorithm, probabilistic neural network (PNN) was employed to decide location of the aircraft icing. A database for the net training and test was generated in this section, and test result of the detection net was discussed. Accuracy of the constructed network is considered to be acceptable. Finally, Section 5 contains a general conclusion of this paper; some issues that highlight our future direction are also discussed.

\section{Flight Dynamics Model}

2.1. Ice Effect on Dynamics. In [8] Bragg et al. proposed a representative model of the ice effect on aircraft dynamics:

$$
C_{(*) \text { iced }}=C_{(*) \text { clean }}\left(1+\eta_{\text {ice }} k_{C^{*}}\right),
$$

where $\eta_{\text {ice }}$ is an icing severity parameter, $k_{C^{*}}$ is the coefficient icing weight which depends on the parameter being modified, $C_{(*) \text { clean }}$ is the clean (not iced) aircraft parameter, and $C_{(*) \text { iced }}$ indicates the iced parameter. In our work, dynamic model of the aircraft is established based on the NASA Twin Otter icing research airplane. Both clean and iced parameters of this aircraft are detailed in Table 1 [8]. The iced parameters in the table are representative of icing severity $\eta_{\text {ice }}=0.2$; $k_{C^{*}}$ could then be calculated as the associated slope from particular parameters under different icing locations. In this paper, similar to [9], a long-period continuous accretion of ice is captured by setting $\eta_{\text {ice }}$ to increase with time. The differential equation

$$
\frac{d}{d t} \eta_{\text {ice }}=N_{1}\left(1+N_{2} \eta_{\text {ice }}\right) C_{\eta}
$$

is used as the model of ice accumulating on airframe, where $C_{\eta}$ represents the conduciveness of the atmosphere to icing. 
TABle 1: Dynamic parameters of Twin Otter in clean and iced configurations.

(a)

\begin{tabular}{lcccccccccc}
\hline & $C_{Z 0}$ & $C_{Z \alpha}$ & $C_{Z q}$ & $C_{Z \delta e}$ & $\bar{C}_{x 0}$ & $K$ & $C_{m 0}$ & $C_{m \alpha}$ & $C_{m q}$ & $C_{m \delta e}$ \\
\hline Clean & -0.380 & -5.660 & -19.970 & -0.608 & -0.041 & 0.052 & 0.008 & -1.310 & -34.200 & -1.740 \\
Wing & -0.380 & -5.342 & -19.700 & -0.594 & -0.050 & 0.053 & 0.008 & -1.285 & -33.000 & -1.709 \\
Tail & -0.380 & -5.520 & -19.700 & -0.565 & -0.046 & 0.053 & 0.008 & -1.263 & -33.000 & -1.593 \\
Both & -0.380 & -5.094 & -19.700 & -0.550 & -0.062 & 0.057 & 0.008 & -1.180 & -33.000 & -1.566 \\
\hline
\end{tabular}

(b)

\begin{tabular}{lcccccccccccccc}
\hline & $C_{Y \beta}$ & $C_{Y p}$ & $C_{Y r}$ & $C_{Y \delta r}$ & $C_{l \beta}$ & $C_{l p}$ & $C_{l r}$ & $C_{l \delta a}$ & $C_{l \delta r}$ & $C_{n \beta}$ & $C_{n p}$ & $C_{n r}$ & $C_{n \delta a}$ & $C_{n \delta r}$ \\
\hline Clean & -0.6 & -0.2 & 0.4 & 0.15 & -0.08 & -0.5 & 0.06 & -0.15 & 0.015 & 0.1 & -0.06 & -0.18 & -0.12 & -0.001 \\
Both & -0.48 & -0.2 & 0.4 & 0.135 & -0.072 & -0.45 & 0.06 & -0.135 & 0.0138 & 0.08 & -0.06 & -0.169 & -0.11 & -0.001 \\
\hline
\end{tabular}

In (2), the coefficients $N_{1}$ and $N_{2}$ are determined from an assumed icing severity profile characterized by the duration time of icing encounter, which is denoted by $T_{\text {cld }}$, and the final and middle values of the icing severity, $\eta_{\text {ice }}\left(T_{\text {cld }}\right)$ and $\eta_{\text {ice }}\left(T_{\text {cld }} / 2\right)$, respectively.

In this paper, the scenario discussed is assumed to be a period of steady level flight with disturbances through a "cloud" of potential icing conditions. The icing encounter is characterized by the duration time $T_{\mathrm{cld}}$ and the icing severity parameters at $T_{\text {cld }}$ and $T_{\text {cld }} / 2$. For all the simulations discussed herein, conduciveness of the atmosphere to icing is assumed to be a raised cosine as

$$
C_{\eta}(t)=\frac{1}{2}\left[1-\cos \left(\frac{2 \pi t}{T_{\text {cld }}}\right)\right]+d_{\eta} .
$$

Note that uncertainty/bias of this conduciveness model is included in $d_{\eta}$. Substituting $T_{\text {cld }}, \eta_{\text {ice }}\left(T_{\text {cld }}\right)$, and $\eta_{\text {ice }}\left(T_{\text {cld }} / 2\right)$ into (2)-(3) and considering an ideal situation as the conduciveness model uncertainty/bias being $d_{\eta}=0, N_{1}$ and $N_{2}$ are determined as

$$
\begin{aligned}
& N_{2}=\frac{\eta_{\text {ice }}\left(T_{\text {cld }}\right)-2 \eta_{\text {ice }}\left(T_{\text {cld }} / 2\right)}{\left[\eta_{\text {ice }}\left(T_{\text {cld }} / 2\right)\right]^{2}}, \\
& N_{1}=\frac{2}{N_{2} T_{\text {cld }}} \ln \left[1+N_{2} \eta_{\text {ice }}\left(T_{\text {cld }}\right)\right],
\end{aligned}
$$

where $\ln (*)$ indicates the natural logarithm function.

Two icing encounter scenarios plus the clean aircraft case will be investigated in this paper, as depicted in Figure 1. For the moderate icing encounter, $T_{\text {cld }}=600, \eta_{\text {ice }}\left(T_{\text {cld }}\right)=0.2$, and $\eta_{\text {ice }}\left(T_{\text {cld }} / 2\right)=0.12$. For the severe $/$ rapid icing encounter, $T_{\text {cld }}=300, \eta_{\text {ice }}\left(T_{\text {cld }}\right)=0.3$, and $\eta_{\text {ice }}\left(T_{\text {cld }} / 2\right)=0.2$. To fully understand performance of the aircraft undertaking ice, a total of 900 -second simulation for all the investigated scenarios will be discussed.

2.2. Nonlinear Dynamics. Motion equations adopted in this paper borrow directly from the 6 degree-of-freedom quasistate nonlinear aircraft dynamics [10]. Clean and iced parameters of icing severity $\eta_{\text {ice }}=0.2$ are detailed in Table 1 . For all cases, the work in this paper is simulated with an initial condition of steady level flight at altitude $3500 \mathrm{~m}$ and velocity

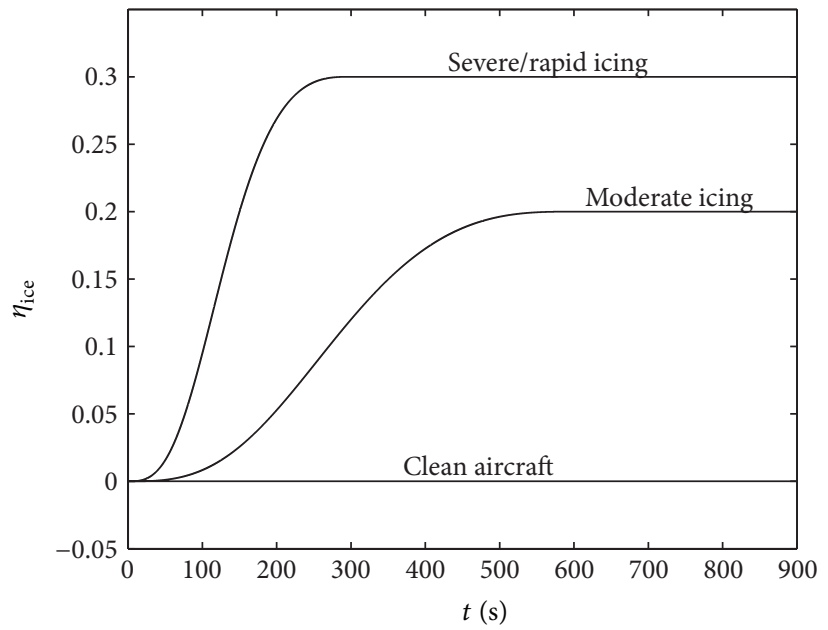

Figure 1: Two icing scenarios and the aircraft clean case.

$70 \mathrm{~m} / \mathrm{s}$. At the beginning of the simulation, icing severity of the aircraft is 0 while during the simulation period, the icing severity takes the shape determined as in (2)-(4) or as in Figure 1.

2.3. Disturbances and Measurement Noise. Performance of the iced aircraft under different disturbances and measurement noise was discussed in [11]. A further research work of the microbust and gravity wave effects on the aircraft was presented in [12]. In our work, both disturbances and measurement noise are modeled based on $[9,13]$ as sample paths of zero-mean, band limited white Gaussian noise with bandwidth $50 \mathrm{~Hz}$. Linearized relation of aircraft motion equations yields $V \approx u, \alpha \approx w / V$, and $\beta \approx v / V$ between aircraft wind and body axes. Intensity of disturbances is modeled as perturbation to velocities along body axes, namely, $\dot{u}_{w}, \dot{v}_{w}$, and $\dot{w}_{w}$ :

$$
\begin{aligned}
& \dot{V}_{w} \approx \dot{u}_{w}, \\
& \dot{\alpha}_{w} \approx \frac{\dot{w}_{w}}{V}, \\
& \dot{\beta}_{w} \approx \frac{\dot{v}_{w}}{V} .
\end{aligned}
$$


For all the simulations discussed herein, a most severe level of the disturbance is adopted as $d_{p}=\dot{u}_{w}=\dot{v}_{w}=\dot{w}_{w}=0.40 \mathrm{~g}$. Intensities of measurement noise are chosen based on specifications of the simulated aircraft sensor resolutions; detailed information on instruments of aircraft state and control surfaces is presented in [14].

\section{Inflight Parameter Identification}

3.1. Hinf ID Algorithm. In [7] we have discussed the Hinf parameter ID framework for the time-invariant system; a state-space system in the form of

$$
\begin{gathered}
\dot{x}=A(x, v) \chi+b(x, v)+d_{p}, \\
y=x+d_{m}
\end{gathered}
$$

was used. In (6), $x \in R^{n}$ is system state vector, $y \in R^{n}$ is the measured state vector, and $v \in R^{i}$ indicates input of the system. In (6), the state-space form is linear with the parameter vector $\chi \in R^{r}$, while $A(x, v)$ and $b(x, v)$ could include nonlinear terms of $x$ and $v$. Disturbance is represented by $d_{p} \in R^{n}$ in the model, and $d_{m} \in R^{n}$ is the system measurement noise.

Time-varying algorithm of the Hinf ID technique considers an assumed linear differential model of the parameter evolution as

$$
\dot{\chi}=H \chi+K d_{\chi},\left.\quad \chi\right|_{t=0}=\chi_{0},
$$

where $H \in R^{r \times r}$ and $K \in R^{r \times s}$ are coefficient weights and $d_{\chi} \in$ $R^{s}$ indicates any uncertainty/bias between the linear terms in (7) and the actual value of $\chi$ differential.

To obtain (7) to be used by time-varying Hinf algorithm for the icing problem, noting that $\chi_{0}=C_{(*) \text { clean }}$ and $\chi=$ $C_{(*) \text { iced }}$, we could have

$$
\chi=\chi_{0}\left(1+K_{C^{*}} \eta_{\text {ice }}\right) .
$$

Combining (2)-(3), the differential form of (8) is in the form of

$$
\dot{\chi}=\chi_{0} K_{C^{*}} N_{1}\left(1+N_{2} \eta_{\text {ice }}\right) \times\left\{\frac{1}{2}\left[1-\cos \left(\frac{2 \pi t}{T_{\text {cld }}}\right)\right]+d_{\eta}\right\} .
$$

At starting point of the icing encounter, $t=0, \eta_{\text {ice }}=0$; (9) yields

$$
\left.\dot{\chi}\right|_{t=0}=\chi_{0} K_{C^{*}} N_{1} d_{\eta}
$$

From (7) and (10), we could have

$$
H \chi_{0}+K d_{\chi}=\chi_{0} K_{C^{*}} N_{1} d_{\eta}
$$

In (11) $\chi_{0}$ indicates clean aircraft parameters, and $K_{C^{*}}$ is the coefficient weight corresponding to the parameter being discussed; both $d_{\chi}$ and $d_{\eta}$ represent (unknown) uncertainty/bias within the model. Also, considering (1)-(3), note that the aircraft icing model adopted in this paper is driftless, which means that ice accretion is induced by exogenous icing conditions only; thus inherent dynamic parameter of the system does not enter the evolution differentials in (7); hence $H \doteq 0$. From (11), the uncertainty/bias weight $K$ adopted by time-varying Hinf algorithm for the icing problem herein is dependent on the parameters being examined (although the real relation might not be derived due to the existence of unknown $d_{\chi}$ and $d_{\eta}$ ). In our study a value of $K=\chi_{0} K_{C^{*}} N_{1}$ will be used, where $N_{1}$ corresponds to the value of moderate icing determined as in (4).

For the system described in the form of (6) and for the aircraft icing problem discussed herein, the time-varying algorithm of Hinf ID technique involves a disturbance attenuation level $\gamma$ between the target estimation result $(\chi)$ and the unknown certainty/bias within the estimation model in the form of

$$
\begin{aligned}
& \|\chi-\hat{\chi}\|_{Q}^{2} \\
& \leq \gamma^{2}\left[\left(\left\|d_{p}\right\|_{I}\right)^{2}+\left(\left\|d_{m}\right\|_{I}\right)^{2}+\left(\left\|d_{\chi}\right\|_{I}\right)^{2}+\left(\left\|d_{\eta}\right\|_{I}\right)^{2}\right. \\
& \left.\quad+\left(\left|x_{0}-\widehat{x}_{0}\right|_{P_{0}}\right)^{2}+\left(\left|\chi-\widehat{\chi}_{0}\right|_{Q_{0}}\right)^{2}\right],
\end{aligned}
$$

where $\widehat{\chi}_{0} \in R^{r}$ and $\widehat{x}_{0} \in R^{n}$ are priori estimates of $\chi$ and initial aircraft state $x_{0}$. In this paper, $\widehat{\chi}_{0}$ is chosen as the clean aircraft parameters for all cases; in the meantime $\widehat{x}_{0}$ is the trimmed steady state of the aircraft. The form $\|*\|_{Q}$ is an $L_{2}$ norm with a predefined semipositive weighting function $Q \geq 0$, and $|*|_{Q_{0}}$ is a generalized Euclidean norm $X^{T} Q_{0} X$ with positive weight $Q_{0}>0$. In (12), both $P_{0} \in R^{n \times n}$ and $Q_{0} \in R^{r \times r}$ are determined by the user. Generally (12) provides a guaranteed worst-case performance of the ID algorithm bounded by $\gamma$ for any real $\chi$ and $x_{0}$ (practically could never be obtained without measuring bias) and the uncertainty/bias within the models $d_{p}, d_{m}, d_{\chi}$, and $d_{\eta}$, as long as $\gamma$ is larger than the minimum achievable disturbance attenuation level $\gamma^{*}$.

Time-varying algorithm of the Hinf ID technique is

$$
\left[\begin{array}{c}
\dot{\hat{x}} \\
\dot{\hat{\chi}}
\end{array}\right]=\left[\begin{array}{cc}
0 & A(y, v) \\
0 & H
\end{array}\right]\left[\begin{array}{l}
\hat{x} \\
\hat{\chi}
\end{array}\right]+\left[\begin{array}{c}
b(y, v) \\
0
\end{array}\right]+\Sigma^{-1}\left[\begin{array}{l}
I \\
0
\end{array}\right](y-\widehat{x}),
$$

where $\Sigma=\Sigma(t) \in R^{(n+r) \times(n+r)}$ is defined as

$$
\begin{aligned}
\dot{\Sigma}= & -\Sigma\left[\begin{array}{cc}
0 & A(y, v) \\
0 & H
\end{array}\right]-\left[\begin{array}{cc}
0 & 0 \\
A(y, v)^{T} & H^{T}
\end{array}\right] \Sigma \\
& +\left[\begin{array}{cc}
I & 0 \\
0 & -\gamma^{-2} Q
\end{array}\right]-\Sigma\left[\begin{array}{cc}
I & 0 \\
0 & K K^{T}
\end{array}\right] \Sigma .
\end{aligned}
$$

With initial condition $\Sigma(0)=\operatorname{diag}\left(P_{0}, Q_{0}\right)$. Note that, in (13)(14), the dependence of $A(y, v)$ and $b(y, v)$ differs from (6); in this paper measurement noise is included in the model; both $A(y, v)$ and $b(y, v)$ adopt noise-perturbed measuring of the system state vector.

One critical issue of the Hinf ID algorithm is to determine the minimum disturbance attenuation level $\gamma^{*}$. The time-invariant case has been discussed in $[13,15]$, and in [9] 
a general result was obtained for the time-varying case. Here we adopt the conclusion directly as, by using the partition

$$
\Sigma=:\left[\begin{array}{ll}
\Sigma_{1} & \Sigma_{2} \\
\Sigma_{2}^{T} & \Sigma_{3}
\end{array}\right]
$$

with $\Sigma_{1} \in R^{n \times n}, \gamma^{*} \equiv 1$ could be achieved by specifying $P_{0}=I$ and $Q=\Sigma_{2}^{T} \Sigma_{1}^{-2} \Sigma_{2}$ for any $Q_{0}>0$.

3.2. Hinf ID Simulation Results. Simulation of the proposed Hinf algorithm is conducted in order to evaluate the timeliness and accuracy of the parameter estimates. Baseline scenarios of all the cases presented are the trimmed steady level flight at given altitude $(3500 \mathrm{~m})$ and speed $(70 \mathrm{~m} / \mathrm{s})$. For all scenarios, excitation is provided only by exogenous disturbances. Both clean and iced simulations will be included. Two icing encounters depicted in Figure 1 are considered, and the clean-aircraft simulation is included to investigate the false alarm or a positive icing indication for the clean case.

As in [7], it was determined that moment derivatives along different axes of the aircraft provide useful information for the ice indicated $\left(C_{m \alpha}, C_{m \delta e}, C_{l p}, C_{l \delta a}, C_{n \beta}\right.$, and $\left.C_{n \delta a}\right)$. Generally the force parameters along body $z$-axis converge too slowly and the $x$-axis force parameters are too sensitive to noise. For all cases discussed in this paper, baseline scenario of the simulation is trimmed at a steady level flight, and the ID technique is expected to provide a continual monitoring of the aircraft icing status. It adopts disturbance as sole excitation for the system. As no control surface input is involved, it is not possible to identify the controllability parameters $\left(C_{m \delta e}, C_{l \delta a}\right.$, and $\left.C_{n \delta a}\right)$; additionally through simulation work it was determined that $C_{l p}$ is too sensitive to disturbances. Hence, only the stability parameters along longitudinal $\left(C_{m \alpha}\right)$ and lateral/directional $\left(C_{n \beta}\right)$ axes will be used in our study.

One issue that needs to be addressed prior to the ID simulation is the choosing of an appropriate $Q_{0}>0$ as in (14). In this paper, $Q_{0}=\left(1 \times 10^{-4}\right) I$ is used for the longitudinal parameters and $Q_{0}=\left(1 \times 10^{-2}\right) I$ for lateral/directional estimates. Also, a value of $\gamma>\gamma^{*} \equiv 1$ is used, as through simulation we found that $\gamma=\gamma^{*} \equiv 1$ could result in a numerically unstable computation. For longitudinal estimates, $\gamma=2$, and for lateral/directional estimates, $\gamma=4$. Generally there is not a universal standard for choosing either $Q_{0}$ or $\gamma$; the results presented herein are based on a trialand-error work of the authors. While a future modification could be included, current performance of the proposed ID framework is presented and discussed as follows.

For all scenarios discussed in this paper, the simulation lasts 900 seconds. In [7], to examine flight safety and passenger-ride quality of the aircraft, a time history of the aircraft response under the designed control input was included. In this paper, safety and comfortableness of the aircraft with an increasing ice effect and a most severe disturbance are also of our concern. Figure 2 represents an example of the aircraft response history up to 900 seconds. In the interest of brevity, only clean and the severe/rapid case of wing-tail both icing was presented (which, by intuition, is decided as the worst case of icing). Given that no external control input is included, most of the state variables remain stable around the trimmed value. Based on aircraft pitch/rolling angle, and the overload along body $z / y$-axis, passenger-ride quality of the aircraft is considered to be acceptable. Altitude of the aircraft undertakes a severe change in the simulation, which descends up to $3,000 \mathrm{~m}$ in the 900 -second simulation. While in reality, pilots could take actions to deal with the altitude loss, in this work a descending of $3,000 \mathrm{~m}$ in $15 \mathrm{~min}$ is considered to be with redeemable margin of safety. No pilot action is included, and the overall system adopts exogenous disturbance signal as input only.

Parameter ID results of the Hinf algorithm is shown in Figures 3-5. Clean aircraft ID result is shown in Figure 3, while moderate/severe case for wing-tail both icing is in Figures 4 and 5, respectively. Note that, in all the figures, the estimated parameters have been normalized with the clean aircraft value; take $C_{m \alpha}$ as an example, $\bar{C}_{m \alpha}=: C_{m \alpha \text { (iced) }} /$ $C_{m \alpha \text { (clean) }}$, wherein $\bar{C}_{m \alpha}$ is the result presented.

For all the figures, in Figures 3-5, 25 runs of the simulation were included to realize different disturbance/measurement noise paths. An average performance of the 25 runs is represented as dashed line in the figure; thick solid line indicates real value of normalized parameter. For clean aircraft, as in Figure 3, both longitudinal and lateral/directional estimates vary significantly, which is caused in part by the random disturbance/noise effect and in part by the numerical sensitiveness of the Hinf algorithm. Generally, the estimate for the clean aircraft case does not exceed the icing severity of $\eta_{\text {ice }}=0.1$, as indicated by the dotted line in Figure 3. This is considered to be sufficient in the fact that, in [7], 5 levels of icing severity $\{0.2,0.4,0.6$, $0.8,1.0\}$ were discussed, and the parameter ID for clean case presented herein does not trespass between different levels.

Simulation results for the iced aircraft are given in Figures 4 and 5. Moderate icing case is shown in Figure 4 and severe icing in Figure 5. Average performance of the 25 ID simulation runs is depicted by dashed lines in the figures. For lateral/directional identification, the estimate is very accurate, and the estimated parameter corresponds to the real value very well. For longitudinal parameter, a certain delay was encountered for various icing levels denoted by dotted lines. Generally as in [7], 5 levels of the aircraft icing were adopted, and we hope to decide the icing status before the next level is actually reached. For moderate icing in Figure 4, the estimate is considered to be sufficient in the fashion of time, as a deeper probe indicates that the average performance yields a delay time of no longer than 41.5 s. For the severe icing in Figure 5, delay time of the longitudinal estimates is relatively large; a maximum delay of about $100 \mathrm{~s}$ was encountered for the highest level of $\eta_{\text {ice }}=0.3$ (indicated by the dotted line at bottom). However, note that although the delay was high, estimated parameter and the real value generally belong to the same level of icing; in such sense the ID algorithm discussed herein is still considered to be applicable.

One issue which the authors would like to mention is the "drift" of Hinf estimated parameters. As in Figure 3, a certain (constant) bias exists between the average performance and real value. Also in Figures 4 and 5, particularly for 

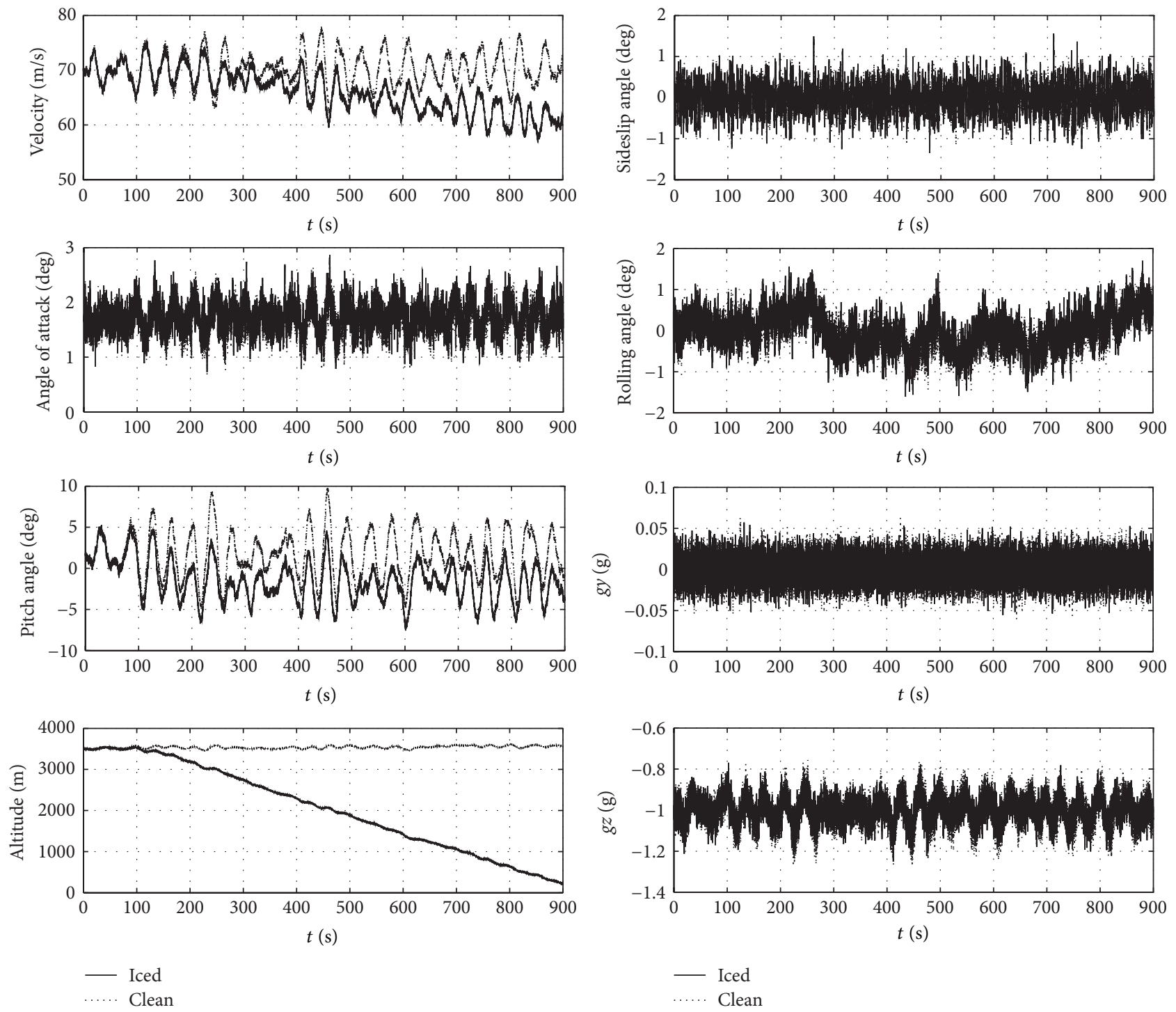

FIGURE 2: Aircraft response, clean, and wing-tail severe icing.

the longitudinal estimates, as can be seen from the average performance, an "advanced indication" of the icing level was encountered. This does not correspond to theoretical characteristics of the Hinf algorithm in the fact that, for the clean case, the estimated value should be twined around the real parameter, and for the iced case, a delay should be encountered as the Hinf algorithm functions based on a historical examination of the system. What adds to the complicatedness of this issue is that although the lateral/directional identification takes exactly the same form as longitudinal estimates, the above-mentioned phenomena were never found. Although the authors are still not with ascertained conclusions upon this issue, this could be caused due to nonlinear terms within longitudinal equations of the aircraft. For all scenarios in this paper, the aircraft is trimmed as steady level flight; lateral/directional state variables are set to 0 , while the longitudinal velocity, angle of attack, and so forth are not; certain nonlinearity could therefore be induced in the equations. The "drift" issue belongs to the algorithm stability analysis, and the "advanced indication" problem could be examined based on a frequency-domain analysis. While this part of the work might be forwarded in the future, currently the authors are mainly focused on application of the Hinf algorithm towards aircraft icing; in this paper, instability or isochronism of the algorithm is expected to be tolerated by the neural networks, as described in the following section.

\section{Icing Characterization}

The objective of icing characterization work is to detect and classify the ice accretion based on sensor data and parameter ID results. In this paper we adopt a conservative stance that sensor data is not included, and only the icing location detection will be discussed. The "detection" introduced herein is slightly different with what has been used in IMS in the 

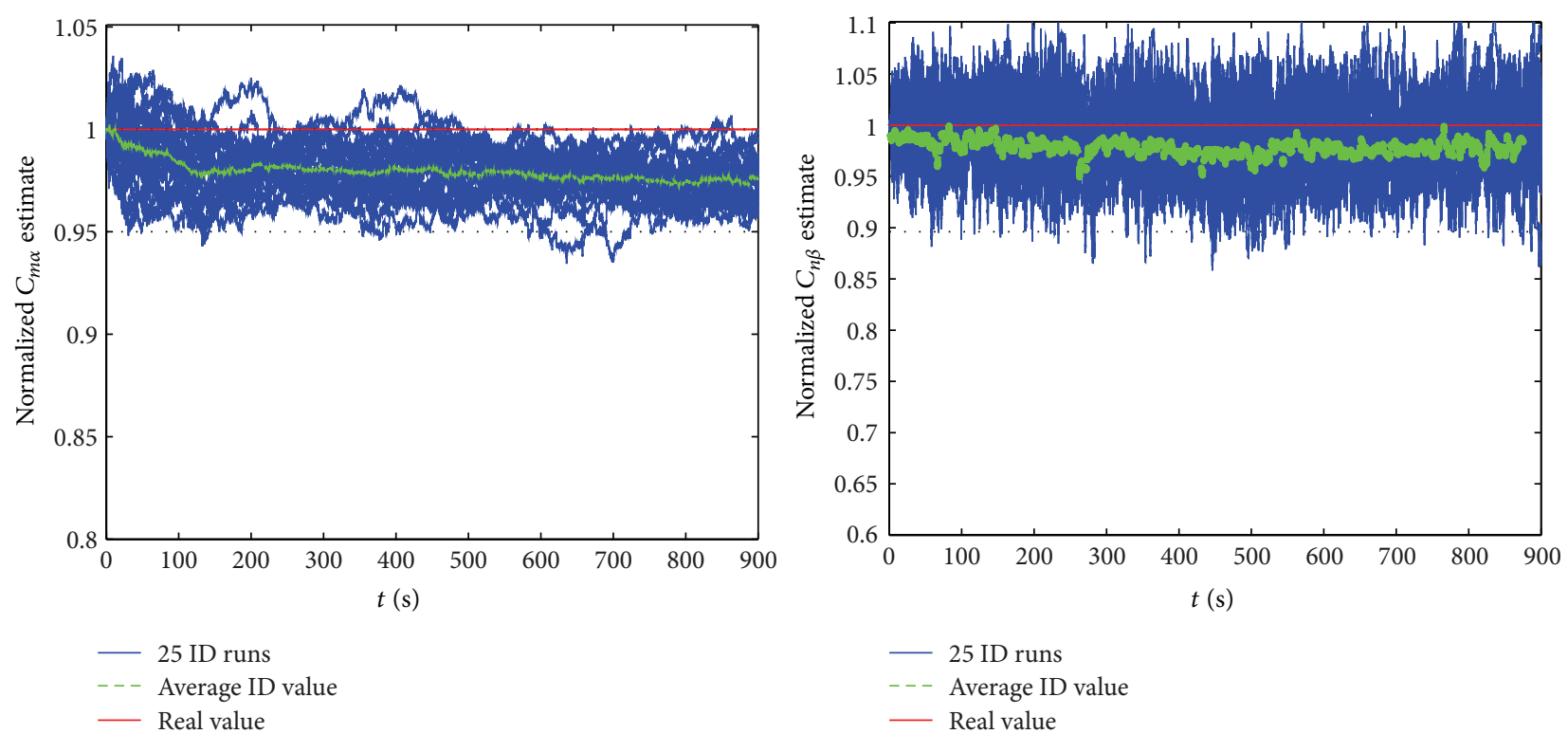

FIGURE 3: ID results for clean aircraft.
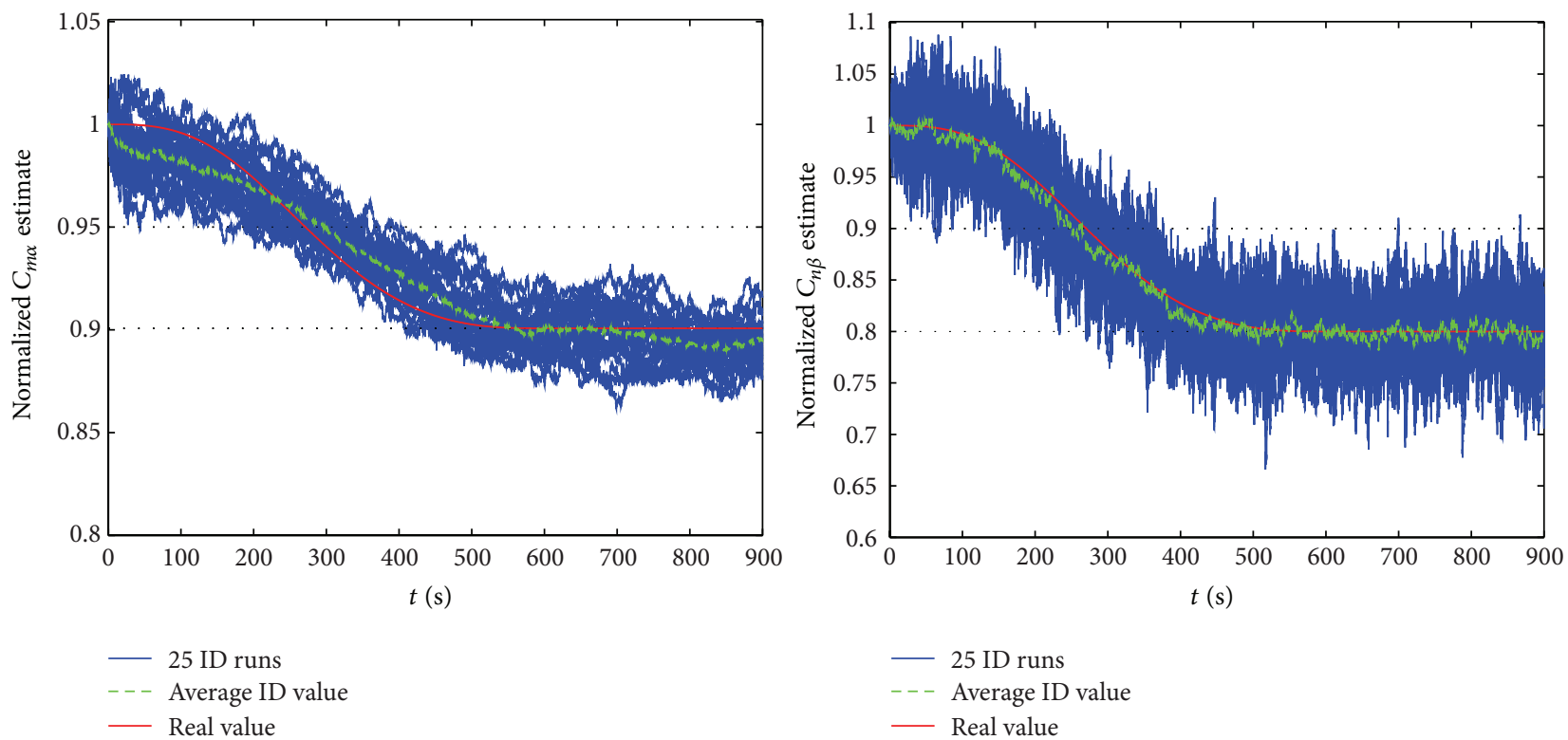

FIGURE 4: ID results for moderate icing scenario.

fact that in IMS "detection" only refers to a determination on whether the aircraft has encountered ice accumulation, while in our study, however, icing detection work is additionally expected to provide timely information about the location where the ice has accumulated. Due to the shortness of aircraft iced data, currently only 4 scenarios of the icing cases are included in our work: clean, wing icing, tail icing, and wing-tail both icing.

Previous work by authors reported in [7] is focused on icing location detection in a short period. Dynamic parameters of the aircraft were assumed to be time-invariant during the parameter ID maneuver, which was induced by a specifically designed control surface input; moment derivatives along different axes of the aircraft were delivered to the icing detection network, and icing location detection could be accomplished with a very high degree of accuracy.

In this study we mainly address the icing location detection for a more common steady level flight, where the ice is accreting gradually on the aircraft, and hence dynamic parameters of the aircraft are varying in the fashion of time. Identically, the icing detection work reported herein adopts estimated parameters from the Hinf ID algorithm. For all scenarios discussed in this study, however, it is assumed that pilot input is not included, and exogenous disturbance signal 

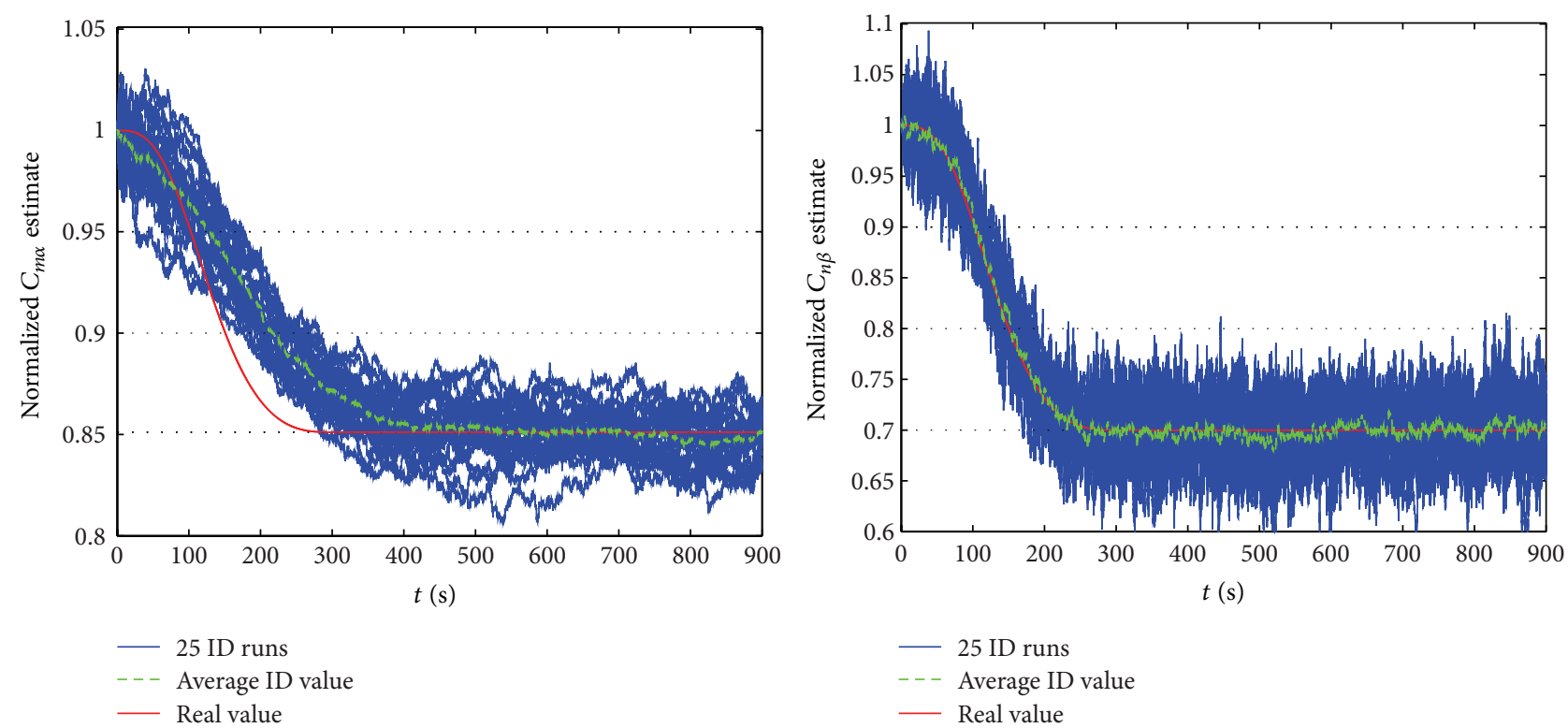

FIGURE 5: ID results for severe/rapid icing scenario.

serves as the sole input for the system. Due to the absence of excitation input, effectiveness of the parameter ID technique might be limited, as some controllability parameters could not be estimated. Another source of information therefore is expected to be included to bridge this potential gap. Also, in [7], an overall detection error of only $0.30 \%$ was achieved while in this study, generally a larger error is acceptable in the fact that the ice accretion is assumed to take place over a long period (up to 5-10 minutes) with a broader margin of safety, and precipitation of icing accidents is less likely in the absence of pilot action.

As in $[6,9,13]$, IMS was restricted to longitudinal dynamics of the aircraft. In the authors' work, lateral/directional analysis is included in the model, which therefore adds to the complicatedness of our study. Also, for IMS work, icing severity classification was discussed; in our work, currently the authors decide not to spend much time upon this issue. This decision was made mainly based on twofold. First we are currently focused on detection of the aircraft icing, and although icing severity could be adopted as a quantificational indication of ice effect, it provides very limited information for the notification of pilot, as the pilot generally is not clear (or concerned) about the meaning of a numerical data $\eta_{\text {ice }}=$ 1.0. This actually represents a dilemma of our icing detection work in the fact that although a quantitative description of ice accretion is necessary, eventually we still need to estimate our work from a qualitative aspect, which might be modeled based on a large-volume data of the pilot assessment. Additionally, through preliminary CFD inspection of the aircraft dynamics we do have certain suspicion upon accuracy of the icing model in (1). While a general detection work based on (1) using neural networks is believed to be with sufficient robustness for further study, a specified classification of icing severity might not. Due to these two reasons, while in future studies we will report the classification work of icing severity (probably based on our own iced aircraft model), currently this part of the work is not presented.

Icing detection in this paper is established by using PNN $[16,17]$. As the detection network is expected to decide location of the aircraft icing, the net output layer contains 4 knots, each of which corresponding to certain pattern of the aircraft icing (clean, wing icing, tail icing, and wingtail both icing). The activation of a certain knot is used for the indication of location deciding. Input layer of the PNN includes parameter estimate results from the Hinf ID technique. Also, as no excitation input from the pilot is included in the system, effectiveness of Hinf technique might be limited. To fill this gap, this paper adopts the concept of "excitation measure" of aircraft as in [18]; the bias from initial state of the aircraft is defined as: $P_{\theta}=\theta-\theta_{0}$ and $P_{H}=H-H_{0}$, where $\theta_{0}$ and $H_{0}$ indicate initial state of the aircraft. Both $P_{\theta}$ and $P_{H}$ will be adopted in the input layer of the network.

The PNN input data, including parameter estimate $\left(C_{m \alpha}\right.$, $\left.C_{n \beta}\right)$ and excitation measure $\left(P_{\theta}, P_{H}\right)$, are sampled and stored at a 10-second interval. The detection network uses $30 \mathrm{~s}$ of the stored data. Instant value of the input data is also adopted by the detection net. Therefore input layer uses a total of 16 data, 4 samples of each term, for the icing location estimation work. This batching of the passed 30-second parameter estimates and excitation measures were used to take advantage of any consistent trends within the data. However, a delay time of $30 \mathrm{~s}$ will be caused. In previous paragraphs we have discussed the tolerance of possible network detection error. As the ice is modeled to accumulate over a long period, and generally handling events will not take place in the absence of pilot action, this detection delay of $30 \mathrm{~s}$ is considered to be acceptable in our study.

Once structure of the PNN detection net is decided, a database for the training and test of the network needs to be generated. Basically, this database is expected to envelope all 
certain situations that might occur when the net is practically deployed. In the current stage of our study, four scenarios of the icing cases including clean, wing, tail, and wing-tail both icing are discussed. For each icing case, two shapes of the icing severity accretion model depicted in Figure 1 will be included. Moreover, as discussed in the previous section, certain bias and an "advanced indication" might be encountered when the parameter ID technique is used. The network is expected to tolerate such potential deficiencies. A large volume of the parameter ID simulation needs to be included in order to capture the trends of the Hinf algorithm average performance.

After a proper database is generated, another issue which we need to consider is selecting from this database for the net training and test data. Typically, data used for the net training and test must be separated strictly; also test data generally should exceed about $25 \%$ of the entire data volume, with the intention that this could help to suppress the "athlete-referee" problem-if the network is trained and tested based on a very same database (serving as both athlete and referee), although accuracy of the net could be achieved with sufficient training efforts, this network is still useless for the practical deployment in the fact that this net has been shaped particularly and exclusively for the training data [19].

In summary, we have run simulations corresponding to different icing cases and icing severities as follows:

(i) pattern 0: clean aircraft;

(ii) pattern 1: wing icing case, moderate and severe/rapid icing;

(iii) pattern 2: tail icing case, moderate and severe/rapid icing;

(iv) pattern 3: wing-tail both icing case, moderate and severe/rapid icing.

Also in order to capture the richness of unknown disturbance/noise impact on the system, different sample paths were repeated for each of the 4 patterns. Totally 60 simulations were performed for pattern 0 (clean aircraft), of which 40 runs were used for training and the remaining 20 for test. In the 3 icing patterns, for each icing severity shape, 20 simulations were performed for training and another 10 for the test. Eventually, a database of 240 simulation runs was obtained, wherein 160 were used for training, and the remaining 80 for test. For each sample run in the database, a simulation of 900 seconds was investigated. As the network is designed to decide icing location at an interval of $30 \mathrm{~s}, 30$ decision points are induced by each sample run, and totally this database contains 7,200 points of network employment, wherein 4,800 are used for training and the remaining 2,400 for test. Note that test data occupies $1 / 3$ of the entire data volume; the "athlete-referee" problem could be avoided.

In training stage of the PNN detection net, two parameter estimates $\left(C_{m \alpha}, C_{n \beta}\right)$ and the excitation measures of aircraft $\left(P_{\theta}, P_{H}\right)$ are delivered to the input layer. The input nodes adopt sampled data at $30 \mathrm{~s}, 20 \mathrm{~s}$, and $10 \mathrm{~s}$ prior to the decision time; instantaneous value at the decision time is also included. Nodes within output layer of the detection net are assigned with corresponding patterns. During the
TABLE 2: Detected result for each (actual) icing case.

\begin{tabular}{lcccc}
\hline & \multicolumn{4}{c}{ Network detected case (percent) } \\
& Clean & Wing & Tail & Both \\
\hline Clean & 94.67 & 1.33 & 3.67 & 0.33 \\
Wing iced & 3.83 & 92.51 & 2.83 & 0.83 \\
Tail iced & 4.17 & 1.50 & 92.83 & 1.50 \\
Both iced & 2.33 & 1.00 & 1.67 & 95.00 \\
\hline
\end{tabular}
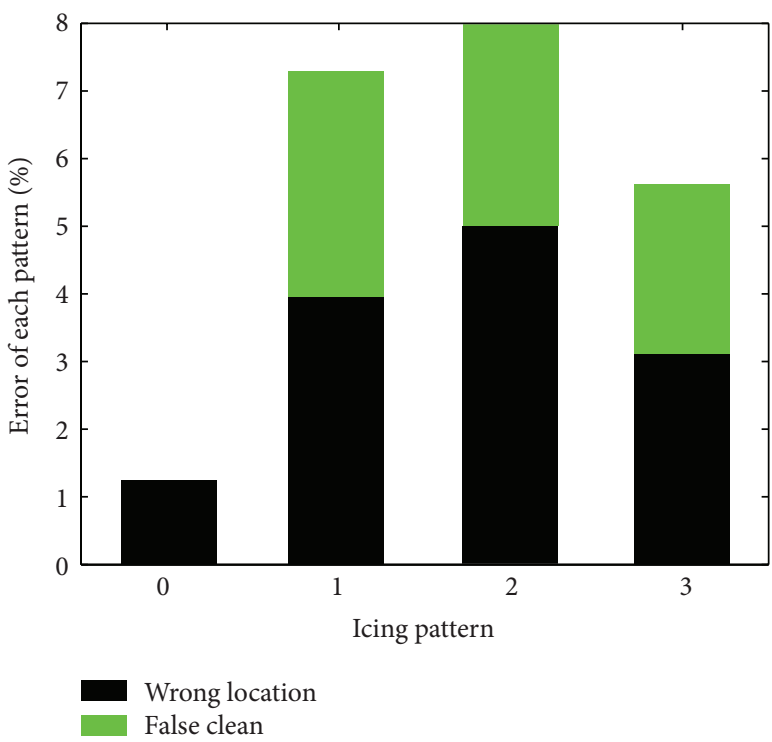

FIGURE 6: Network test error for each icing pattern.

net training stage, one parameter that we need to decide is spread or smoothing factor of the PNN decision-surface shape. Generally a smaller spread yields a stricter standard for pattern classifying of the training data. Although higher pattern-recognition accuracy could be achieved for the training data via a smaller spread choosing, the decision surface constructed might be too sharp for the test data, and a large bias of the net test could be encountered. The choice of spread therefore requires a balance between a "cause" of training data and "effect" of the test data. In our study the authors decide that spread $=3.0$ yields a balance between test accuracy and the net complicatedness.

Net test result is shown in Figures 6 and 7; detailed results are characterized in Table 2. Note that, in Figure 6 and Table 2, detection error was discussed for each of the patterns separately, while Figure 7 investigates an overall test error distribution versus the actual aircraft icing severity. From Figure 6 and Table 2, false-alarm rate of the detection network, or a positive icing indicating the clean case, is $5.33 \%$. In our study, this false-alarm rate is considered to be acceptable. For icing patterns of the aircraft, possible erroneous icing location decision was encountered, as depicted by the deep-color line segments in Figure 6. A detailed result is presented in Table 2; 3.63\% of wing icing, 3.00\% of tail icing, and $2.67 \%$ of both icing test output yields a wrong location, although positive icing was decided. Moreover, we 


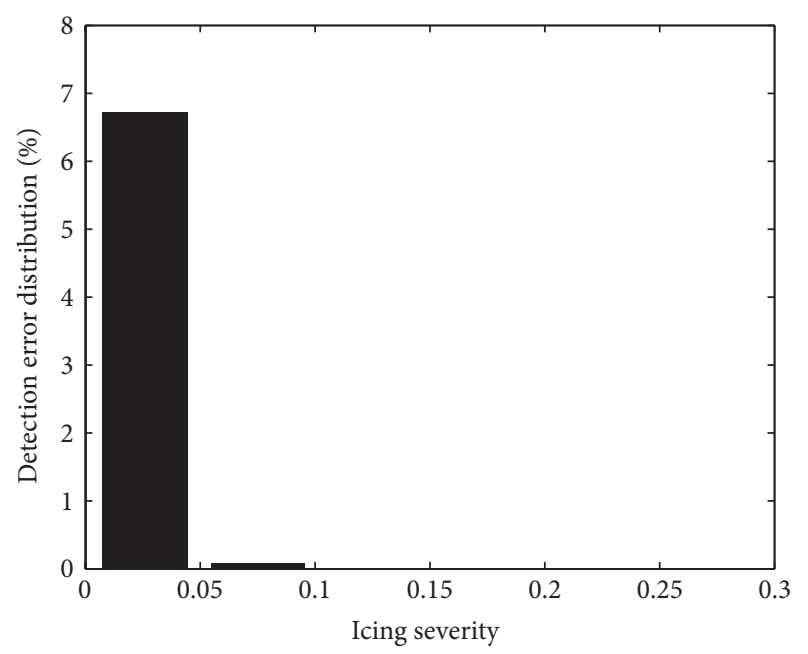

FIGURE 7: Overall detection error versus aircraft (actual) icing severity.

are very concerned about "danger rate" of icing detection, which in our study is defined as a false-clean indication for iced aircraft. This sort of error is presented by light line segments in Figure 6, and based on Table 2 it was decided that the danger rate of net test was 3.83\%, $4.17 \%$, and $2.33 \%$ for each icing pattern, respectively. In summary, for all the 2,400 test samples of the detection net, an overall error rate (including false alarm, wrong-location decision, and danger rate) of $6.25 \%$ was achieved. Distribution of the detection error versus local icing severity of the aircraft is depicted in Figure 7. The whole detection error was encountered in the icing severity threshold below $\eta_{\text {ice }}=0.10$, which is considered to be accurate enough in the fact that as in [7], 5 levels of the icing severity $\{0.20,0.40,0.60,0.80,1.00\}$ were adopted; $\eta_{\text {ice }}=0.10$ still belongs to the first level, and even if a detection error was encountered, the relatively low icing severity would exert very limited impact upon the aircraft, especially as the ice accretion takes place in a long period, and handling event generally will not happen as pilot action is not included.

\section{Concluding Remarks}

This paper introduced a research work on the inflight parameter identification and icing location detection for the iced aircraft. As opposed to the previously reported work for a short period, where the parameters were assumed to be time-invariant, and a system excitation input was specifically designed, this study considers the time-varying nature of the problem. Ice accumulation is modeled as a continuous process, where the effect of the ice upon aircraft dynamics is assumed to be accreted over a long period. Time-varying algorithm of the Hinf parameter identification technique was employed to provide inflight parameter estimates of the aircraft. This technique adopts exogenous disturbances as the system excitation only, and no pilot action is included in the ID framework. Two stability parameters along longitudinal and lateral/directional axis were particularly presented and discussed. Although certain delay of the ID algorithm does exist, it was considered to be acceptable. The icing location detection work in this paper is constructed by using the probabilistic neural network. While different cases of the icing location are classified as different patterns in the net output layer, input layer of the network adopts the Hinf parameter estimate results and also excitation measure of the aircraft. All the input of the detection network was sampled at an interval of $10 \mathrm{~s}$, and the data were windowed at a period of 30 s to take advantage of any potential consistent trend within the data. A database corresponding to different icing cases, ice accumulation processes, and disturbance/noise paths was generated for the net training and test. Test result of the clean aircraft yields a false alarm rate of 5.33\%; also overall detection error of the network is $6.25 \%$. A deeper probe into the error distribution indicates that all the test errors were encountered at the icing severity no more than 0.10 . While the aircraft with such low icing severity is believed to be with sufficient safety margin, the detection network developed in this paper is believed to be applicable for further studies.

As explained in the paper, direction of authors' work has shifted slightly. In our future works we will not spend much of the time upon icing severity classification of the aircraft. The authors plan to further the detection work for more icing cases (aircraft nose, airspeed probe, engine inlet, etc.), and more scenarios of the aircraft flight mission (landing, take-off, etc.) will be investigated. Additionally, although the linearized model advanced by Brag has been used for many years, accuracy of this model does warrant our close interest. We do hope to extract a more accurate as well as applicable model for the aircraft icing problem.

\section{Conflict of Interests}

The authors declare that there is no conflict of interests regarding the publication of this paper.

\section{Acknowledgments}

This work is supported by China's Aerospace Fund and also by Fudan's Graduate Innovation Fund. The authors are also indebted to Qin Lu and Lin Li from the Flight Test Section in Commercial Aircraft Corporation of China (COMAC) in Shanghai, China.

\section{References}

[1] M. Bragg, "Aircraft aerodynamic effects due to large droplet ice accretions," in Proceedings of the 34th AIAA Aerospace Sciences Meeting and Exhibit, AIAA-96-0932, Reno, Nev, USA, 1996.

[2] "Aircraft accident report, inflight icing encounter and loss of control, ATR model 72-212, Roselawn, Indiana, October 31, 1994," Tech. Rep. NTSB/AAR-96/01, National Transportation Safety Board, 1996.

[3] Interim Report on the Accident on 1 June 2009 to the Airbus A330203 Registered F-GZCP Operated by Air France Flight AF 447 Rio de Janeiro-Paris, Bureau d'Enquêtes et d'Analyses pour la Sécurité de l'Aviation Civile (BEA), Paris, France, 2009. 
[4] "Safety Investigation Following the Accident on 1st June 2009 to the Airbus A330-203, Flight AF 447-Summary," (English edition), Paris: Bureau d'Enquêtes et d'Analyses pour la sécurité de l'Aviation civile (BEA), 2012.

[5] T. P. Ratvasky, J. F. van Zante, and J. T. Riley, "NASA/FAA Tail-plane Icing Program Overview," Number AIAA-99-0370, NASA/TM-1999-208901, 1999.

[6] M. Brag, W. Perkins, N. Aarter et al., "An interdisciplinary approach to inflight aircraft icing safety," in Proceedings of the 36th AIAA Aerospace Sciences Meeting and Exhibit, AIAA-980095, Reno, Nevada, 1998.

[7] Y. Dong and J. Ai, "Research on inflight parameter identification and icing location detection of the aircraft," Aerospace Science and Technology, vol. 29, no. 1, pp. 305-312, 2013.

[8] M. Bragg, T. Hutchison, J. Merret, R. Oltman, and D. Pokhariyal, "Effects of ice accretion on aircraft flight dynamics," in Proceedings of the 38 th AIAA Aerospace Sciences Meeting and Exhibit, AIAA-2000-0360, Reno, Nev, USA, 2000.

[9] J. W. Melody, T. Hillbrand, T. Başar, and W. R. Perkins, " $H_{\infty}$ parameter identification for inflight detection of aircraft icing: the time-varying case," Control Engineering Practice, vol. 9, no. 12, pp. 1327-1335, 2001.

[10] Z. P. Fang, W. C. Chen, and S. G. Zhang, Aerospace Vehicle Dynamics, Beihang University Press, Beijing, China, 1st edition, 2005.

[11] M. Bragg, T. Hutchison, J. Merret, R. Oltman, and D. Pokhariyal, "Effects of ice accretion on aircraft flight dynamics," in Proceedings with the 38th AIAA Aerospace Sciences Meeting and Exhibit, number AIAA-2000-0360, Reno, Nev, USA, 2000.

[12] D. Pokhariyal, M. Bragg, T. Hutchison, and J. Merret, "Aircraft flight dynamics with simulated ice accretion," in Proceedings of the 39th AIAA Aerospace Sciences Meeting and Exhibit, AIAA2001-0541, pp. 2001-0541, Reno, Nev, USA, 2001.

[13] J. W. Melody, T. Basar, W. R. Perkins, and P. G. Voulgaris, "Parameter identification for inflight detection and characterization of aircraft icing," Control Engineering Practice, vol. 8, no. 9, pp. 985-1001, 2000.

[14] T. P. Ratvasky and R. J. Ranaudo, "Icing effects on aircraft stability and control determined from flight data," in Proceedings of the 31st Aerospace Sciences Meeting and Exhibit, Reno, Nev, USA, 1993, number AIAA-93-0398.

[15] G. Didinsky, Z. Pan, and T. Basar, "Parameter identification of uncertain plants using $H_{\infty}$ method," Automatica, vol. 31, no. 9, pp. 1227-1250, 1995.

[16] D. F. Specht, "Probabilistic neural networks," Neural Networks, vol. 3, no. 1, pp. 109-118, 1990.

[17] D. F. Specht and P. D. Shapiro, "Generalization accuracy of probabilistic neural networks compared with back-propagation networks," Internal report of Lockheed Palo Alto Research Laboratory, Lockheed Palo Alto Research Laboratory, 1991.

[18] J. Melody, D. Pokhariyal, J. Merret et al., "Sensor integration for inflight icing characterization using neural networks," in Proceedings of the 39th AIAA Aerospace Sciences Meeting and Exhibit, AIAA-2001-0542, Reno, Nev, USA, 2001.

[19] D. F. Zhang, Application in the Design of Neural Networks Using MATLAB, China Machine Press, Beijing, China, 2009. 

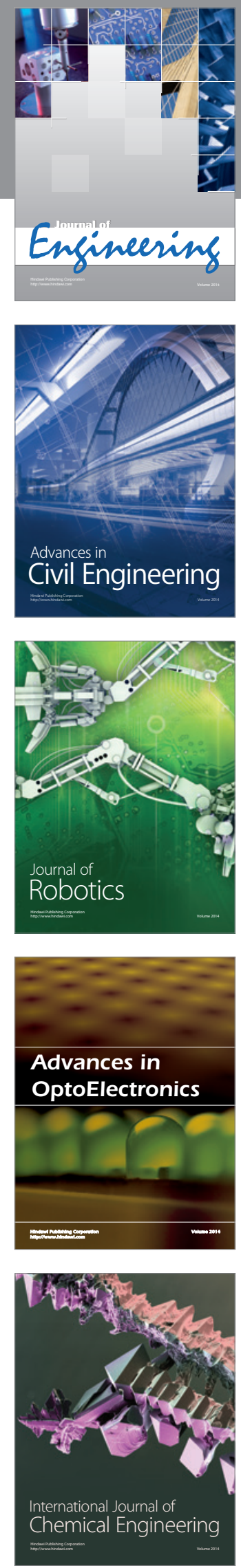

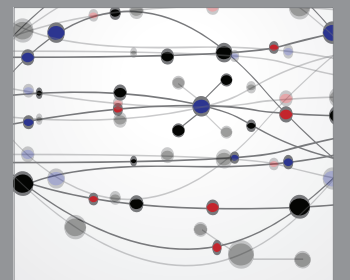

The Scientific World Journal
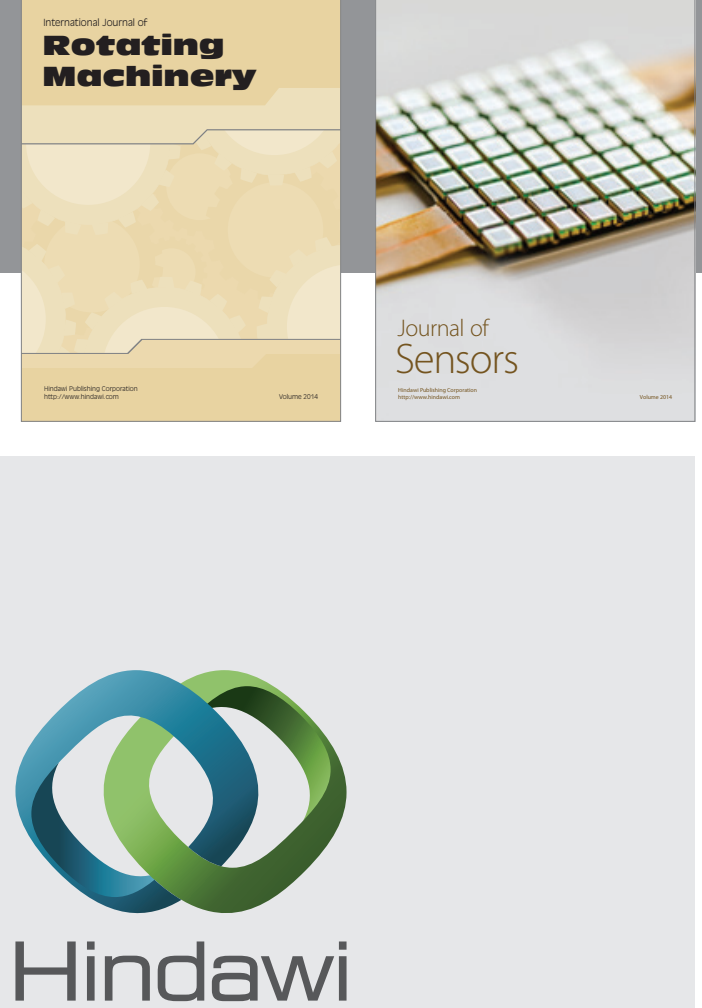

Submit your manuscripts at http://www.hindawi.com
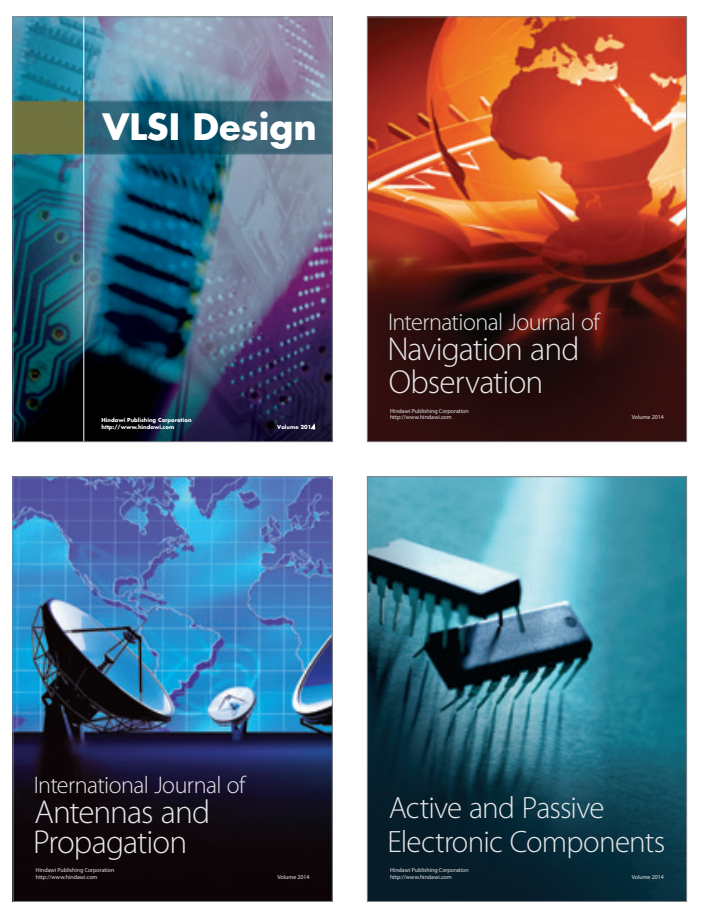
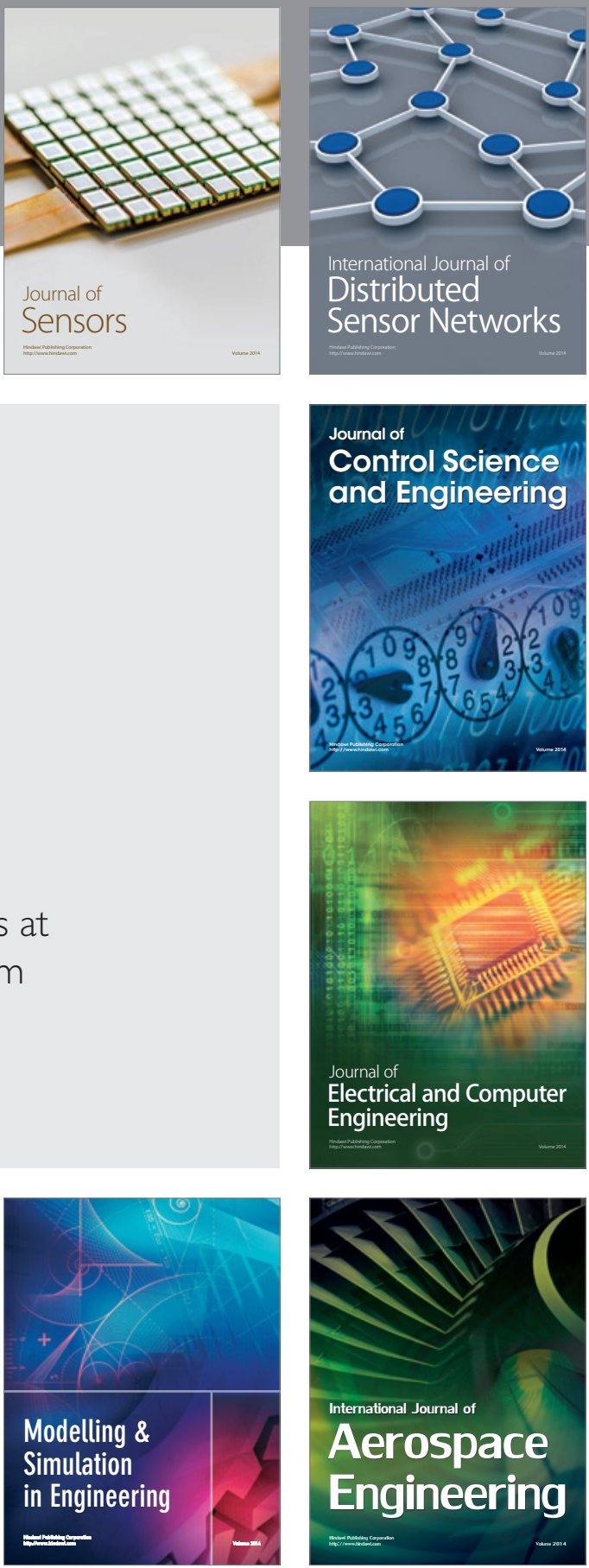

Journal of

Control Science

and Engineering
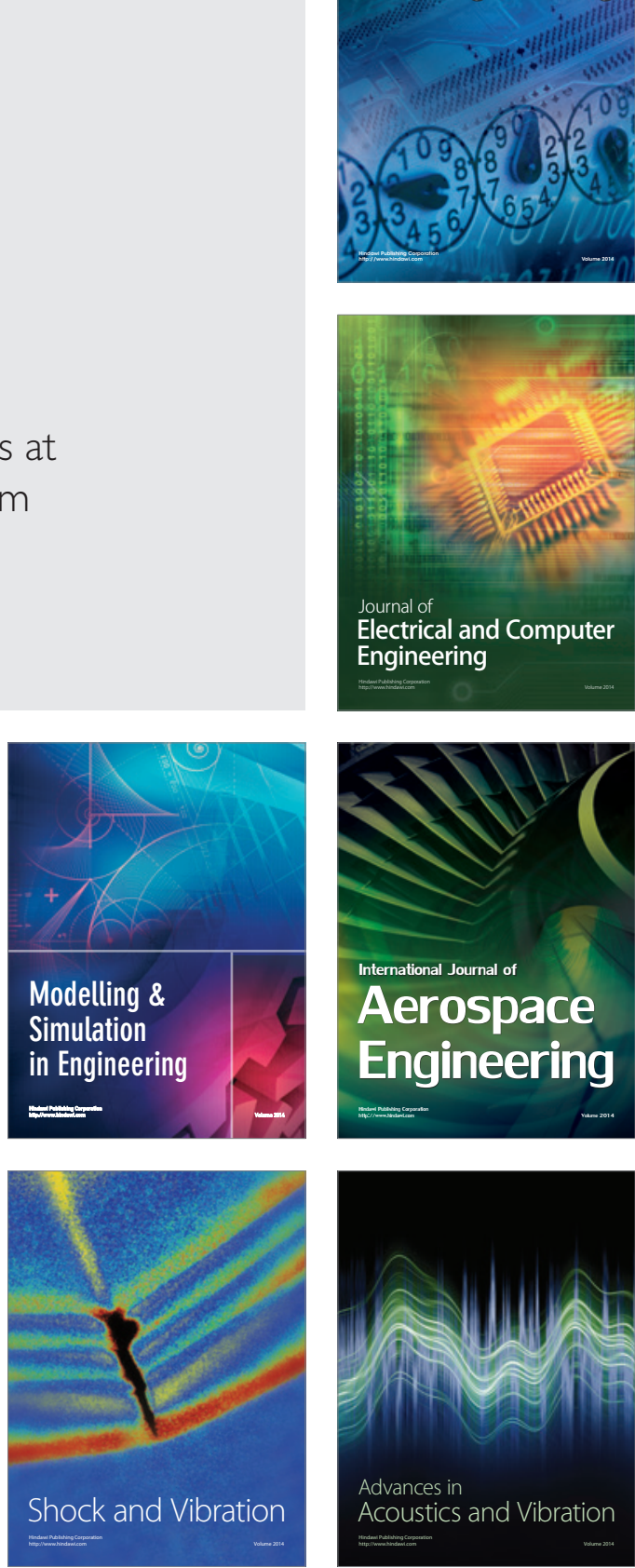